\title{
Social-marketing as a Tool of Behavioral Change in Youths' Personal Development
}

\author{
SHAFAQ HASSAN \\ Quaid-i-Azam University Islamabad, Pakistan \\ ABDUL QAYYUM \\ Faculty of Management Sciences \\ Riphah International University, Islamabad, Pakistan \\ SANA-UR-REHMAN SHEIKH \\ Institute of Management Sciences, \\ University of Balochistan, Quetta, Pakistan \\ SHAMS-UR-REHMAN \\ Faculty of Management Sciences \\ NUML Peshawar Campus, Pakistan
}

\begin{abstract}
This paper aims to study the link between the concept of social marketing and personal development of the youth. More specifically, it aims to identify the internal/external determinants of youth development and design, implement and evaluate the impact of community-based social marketing intervention program upon youth. A mixed methods research design with an overarching participatory paradigm is implemented, which includes a purposive sample of youth between the ages of 18-29. Qualitative methods include focus groups and face-to-face interviews. Quantitative methods included a pretest/posttest quasi-experimental design used to determine whether there is a difference in the personal development of youth. The findings conclude that there is a significant difference in the before and after experimental group when subjects are exposed to social marketing concepts as compared to the control group receiving no such exposure over a two-month time frame. However, there is no difference in the personal development within the experimental group on the basis of gender.
\end{abstract}

Keywords: Marketing, Personal Development, Social Marketing, Youth Development

\section{Introduction}

No society is perfect and social problems are rampant everywhere, more so in under-developed and developing countries (Khalid, 2003). Unfortunately, impatience, restlessness, confusion and frustration have become characteristic of today's youth (Khalid, 2003). In order to counter such attitudes/behaviors, youth need to develop themselves on personal and social levels in order to become resilient in the face of any 
challenges life may bring (Greenwald, Pearson, Beery \& Cheadle, 2006). This highlights the importance of youth development.Although policies on youth development have been far and varied, there has been little action with little progress and long-term viability.

Social marketing is the tool that can be used to bring about changes from the community-based perspective in which long-term behavioral changes are achieved (Andreasen, 2006). Social marketing strengths lie in its comprehensiveness in influencing behavior through voluntary behavior change, catering to the target audience's needs (through marketing techniques) whilst empowering and motivating them and providing clear benefits (through the principle of exchange) to the individual and society(Stead et al., 2007). Therefore there is a dire need for such an awareness and change amongst youth in present rapidly changing time.

For social change to occur an individual must put forward the best course of action needed to decide - whether to promote a certain behavior or set of behaviors or even prevent change (Andreasen, 2006). No doubt, one of the greatest resource or asset of any nation is its youth and since $68 \%$ of the Pakistani population (under 30 years) comprise of the youth, this poses not only challenges but also immense opportunities (Janjua, Ahmed \& Mahmood, 2011). Current study is an attempt to apply the concept of social marketing in order to identify, promote and bring change in certain behaviors for the personal development of youth while identifying the internal and external determinants of youth development.

\section{Literature Review}

The realm of marketing has expanded to include the marketing of non-profits, cause marketing, corporate social responsibility and most recently, social marketing. Social marketing is essentially about influencing behavioral outcomes (Domegan, 2008). What makes social marketing unique is the behavior change (Andreasen, 2002) in general and personal development of youth in particular.

Personal development is the growth of an individual towards self-awareness or realization where one may stand apart from others by developing own thoughts and actions through conceiving personal potentialities and capabilities (Covey, 1998). Youth Development $\mathrm{YD}$, being an ongoing growth process, engages youth in attempting to meet basic personal and social needs, in such a way that is safe, valued, useful and spiritually grounded, in order to build skills and competencies that allows them to be functional and contributive towards society (Pittman, 1993). YD is more viable social development front because of the huge potential among young people.

YD does not mean a succession of some life cycle stages, rather it relates to the "state of comfort and mastery along several emotional and social dimensions" and it assumes that youth will be better equipped to face the challenges of growing up if they function well on a personal and social level whilst maintain strong ties with the community to which they belong (Greenwald et al., 2006).

Social marketing is "the application of commercial marketing technologies to the analysis, planning, execution and evaluation of programs designed to influence the voluntary behavior of target audiences in order to improve personal and social welfare" (Andreasen, 2002).Social marketing has been applied in many diverse situations to influence a vast range of behavior ranging from the marketing of products involved in the social change (oral rehydration solutions, msalarial nets, condoms, etc.) to purely 
behavioral challenges such as sending girls to attend school in under develop countries (Andreasen, 2002). Borrowing from bodies of knowledge such as psychology, sociology, communications theory and anthropology, social marketing has a plethora of tools, concepts, frameworks and approaches which focus on behavioral change (Stead et al., 2007).

Social marketing is also seen as an approach to influencing target groups that exhibit bad behaviors such as smoking, using drugs, not recycling etc. (Andreasen, 2006). Since the main feature of social marketing is about voluntary behavior change, then the change should be sustainable as well. Positive change among youth particularly a comprehensive YD programis possible by social marketing interventions (Greenwald et al., 2006). Present study is an effort to determine the determinants of YD in a developing countryby a qualitative inquiry and to look at the impact of social marketing interventions on YD through an experimental design.

\subsection{Conceptual Framework}

Due to the nature of the current study, the conceptual framework is developed after a qualitative inquiry which is backed by the literature review comprising existing theories.

\section{Qualitative Study}

A total of twelve focus group sessions (6-10 participants each) are held at university campuses in Islamabad and Lahore, Pakistan, where ninety-two males and females of age groups 18-25 participated as shown in Table 1. Participants have a balanced mix of gender i.e. 52\% males and $48 \%$ females and true representation of youth as $37 \%$ are between the ages of $18-20,48 \%$ between the ages of $21-23$ and $15 \%$ between the ages of 24 and 25. Participants are actually students of a public (46\%) and a private (52\%) university, belonging to natural sciences (28\%) and social sciences (72\%) disciplines.

As more in-depth and candid feedback has been required, the researcher formulated more probing questions as per the responses in the form of interviews after each focus group session. The interviews not only validate the findings of the focus group sessions, but also provide more detailed interpretations of the themes emerged from the focus group sessions.

Table 1: Demographic data of focus groups

\begin{tabular}{|c|c|c|c|c|c|c|c|c|c|c|c|c|}
\hline \multirow{2}{*}{$\begin{array}{l}\text { Focus } \\
\text { Gr }\end{array}$} & \multicolumn{2}{|c|}{ Gender } & \multirow[t]{2}{*}{ University } & \multirow[t]{2}{*}{ Department } & \multicolumn{8}{|c|}{ Age (years) } \\
\hline & Male & Female & & & 18 & 19 & 20 & 21 & 22 & 23 & 24 & 25 \\
\hline 1 & 4 & 4 & $\overline{\mathrm{QAU}}$ & Admin Sciences & 2 & & & & 1 & 2 & & 3 \\
\hline 2 & 4 & 2 & QAU & Admin Sciences & & & & 2 & 2 & 2 & & \\
\hline 3 & 5 & 3 & UoL & Admin Sciences & & & & 1 & 4 & 1 & 2 & \\
\hline 4 & 4 & 4 & COMSATS & Engineering & 1 & 1 & 3 & 2 & 1 & & & \\
\hline 5 & 4 & 3 & QAU & Admin Sciences & & & 1 & 2 & & 3 & 1 & \\
\hline 6 & 5 & 5 & QAU & Biology & & & & & & 3 & 4 & 3 \\
\hline 7 & & 5 & QAU & Admin Sciences & 1 & 2 & 2 & & & & & \\
\hline 8 & 6 & & QAU & Admin Sciences & 1 & 2 & 3 & & & & & \\
\hline 9 & 4 & 5 & Preston & Admin Sciences & 2 & 4 & 3 & - & & & & \\
\hline 10 & 4 & 5 & MAJU & Admin Sciences & 1 & 2 & 3 & 3 & & & & \\
\hline 11 & 4 & 4 & UoL & Engineering & & & & 1 & 4 & 2 & 1 & \\
\hline 12 & 4 & 4 & UoL & Physics & & & & 1 & 4 & 3 & & \\
\hline Hassan, & zyyum, s & $k h \& R e h m$ & & 91 & & & & & ISSN: & $520-(-1-20-x$ & 739 & \\
\hline
\end{tabular}




\begin{tabular}{rllllllllll} 
Total & 48 & 44 & 8 & 11 & 15 & 12 & 16 & 16 & 8 & 6 \\
\hline & 92 & 92 & & & & & & & \\
\hline
\end{tabular}

Through a combination of focus groups and face to face interviews, themes emerged are classified under two main headings - internal factors and external factors as shown in Table 2.The external determinants of youth development are further categorized as "proximal" and "distal" leverage points as suggested by (Andreasen, 2006, p. 76-81), meaning factors closer or further away from individuals, still have an influence on youth development. Within the external category, proximal leverage points are identified as family, teachers and friends followed by specific factors within these three categories.

Table 2: Main Determinants of Youth Development

\begin{tabular}{|c|c|c|}
\hline \multicolumn{2}{|c|}{$\begin{array}{l}\text { Downstream Factors- } \\
\text { Internal Determinants }\end{array}$} & $\begin{array}{l}\text { Upstream Factors- } \\
\text { External Determinants }\end{array}$ \\
\hline \multicolumn{2}{|c|}{ DEVELOPMENTAL } & PROXIMAL LEVERAGE POINTS \\
\hline & Personal & $\begin{array}{l}\text { Family } \\
\end{array}$ \\
\hline & Psychological & Teachers \\
\hline & Social & $\begin{array}{ll}\text { Friends }\end{array}$ \\
\hline & Emotional & DISTAL LEVERAGE POINTS \\
\hline \multirow{4}{*}{ Professional } & Cognitive & Education System \\
\hline & & Economic/Political System \\
\hline & Time Management & Social System \\
\hline & Skills/Competencies & Media \\
\hline
\end{tabular}

The main themes identified within the internal determinants category are factors dealing with personal versus professional development. Professional development category includes time management and skills for market including decision-making skills as main themes with highest frequency (8\%). Within the personal development category, four main sub-themes emerged are: psychological, social, emotional and cognitive factors, also suggested by Benson \& Saito (1998).

When questions are asked about what youth development means to you, most interviewees reply that it is a mix of personal and professional grooming and it is not merely professional development. Things mostly concerning to everyone are turbulent economy, political instability, unpredictable security situation, negative and manipulative role of media and ever declining job market. The youth also felt a lack of power, rights and ability to make independent decisions. Again, the root cause or barrier is the inability to step back and realize one's full potentialities and capabilities. So where does this external, highly influential yet uncontrollable environment leave the youth of our nation... to think more and more about things they can control, that is, their own development and well-being. It is important to note that although internal and external influences both shape the individual and one is not independent of the other (Bandura, 1986 as cited in Hastings, 2007), however, due to time limitations, the focus of this study remains on internal influences and the individual's change in thinking/attitude ultimately resulting in a change in behavior (downstream approach).

Subsequently, youth identified personal development as the most important factor to overall development and growth. Personal development includes factors such as thinking ability, emotional stability, maturity, positive attitude, moral values, confidence, courage, self-motivation, self-awareness, tolerance, initiative and pro-activeness, ability 
to deal with various situations and make good decisions accordingly. The major concern for youth is lack of grooming in terms of personal growth, satisfaction and overall development.

\subsection{SHypothesis Development}

As youth identified personal development as an opportunity for growth, selfawareness and an overall grooming to increase one's potential and capabilities, it became apparent that the social marketing program needed to focus and promote these factors of personal development as the target behavior(s), keeping in mind the prevalent barriers to this behavioral change. The following is an illustration of the proposed conceptual framework of the current study.

\begin{tabular}{|c|c|c|c|}
\hline $\begin{array}{c}\text { TARGET } \\
\text { BEHAVIOR } \\
\text { (Behavior } \\
\text { Change) }\end{array}$ & $\begin{array}{c}\text { ESSENCE } \\
\text { (BPS) } \\
\text { (Exchange/ } \\
\text { Competition) }\end{array}$ & $\begin{array}{c}\text { MARKETI } \\
\text { MIX } \\
\text { (Segmentin } \\
\text { Targeting }\end{array}$ & $\begin{array}{c}\text { AUDIENC } \\
\text { BENEFIT } \\
\text { (Consumer } \\
\text { Orientation }\end{array}$ \\
\hline $\begin{array}{l}\text { Uncovering the } \\
\text { barriers to } \\
\text { behaviors \& } \\
\text { selecting which } \\
\text { behavior(s) to } \\
\text { promote } \\
\text { (McKenzie-Mohr, } \\
\text { 2000) }\end{array}$ & $\begin{array}{l}\text { Designing the } \\
\text { program to } \\
\text { overcome the } \\
\text { barriers }\end{array}$ & $\begin{array}{l}\text { Piloting the } \\
\text { program }\end{array}$ & $\begin{array}{l}\text { Evaluating th } \\
\text { program }\end{array}$ \\
\hline $\begin{array}{r}\text { Participatory } \\
\text { Paradigm }\end{array}$ & \multicolumn{2}{|c|}{\begin{tabular}{|l} 
PERSONAL \\
DEVELOPMENT \\
(Covey, 1998) \\
Self-Awareness \\
(Being Pro-active, Independent, \\
Positive and Self-Confident)
\end{tabular}} & $\begin{array}{l}\text { Behavior } \\
\text { Change }\end{array}$ \\
\hline
\end{tabular}

Figure1. Proposed Conceptual Framework of Study

Details of The Integrative Model for Social Marketing (Lefebvre, 2011):

1. Target (desired) Behavior- The social marketing approach deals with the point of view of the audience (POV) and embraces their assumptions or underlying determinants (i.e. beliefs, intentions, self-efficacy, social norms, etc...), the context or the external 
environment of the audience or (i.e. their socio-economic status, family background, living conditions, public policies, etc...) and the consequences or the important outcomes of current or alternative behaviors (i.e. a behavior change through intrinsic, social or other rewards/punishments).

2. Essence: Behaviors, Products \& Services (BPS)- Designing programs that focus on shaping, or targeting incremental behaviors keeping in mind branding (what the behavior, program and sponsor mean to people), relevance (behaviors focused on should be ones that people we work with agree are relevant, possible and believe they are able to do in their daily lives) and positioning (creating an image through understanding of competition and or competing behaviors and providing a mutually beneficial exchange where benefits exceed the costs).

3. The Marketing Mix

- Product (design and features)

- Price (incentives and costs)

- Place (access and opportunities)

- Promotion (communications and experience)

4. The Audience Benefit- The importance of personally relevant benefits which are more short-term and are perceived as more concrete (whether tangible or intangible) as a consequence of their actions.

Based on the literature review and results of initial qualitative study resulting in the subsequent development of the conceptual framework, the following theories are presented resulting in four proposed hypotheses which is tested to achieve research objectives - to design the social marketing program, implement the social marketing intervention program through experimental design and evaluate its effectiveness using both quantitative and qualitative methods.

As social marketing is essentially about voluntary behavior change, it is only obvious that one needs to be cognizant of social marketing's link to the human behavior theories, such as,Social Cognitive Theory, Exchange Theory, and Social Learning Theory.

Social Cognitive Theory explains that individual behavior is influenced by both personal and environmental factors and changes in any of them are hypothesized to render changes in the other (Bandura, 1986 as cited in Hastings, 2007). Key concepts of this theory, such as, observational learning, self-efficacy, outcome expectations, emotional coping responses, enactive learning, rule learning and self-regulatory capability are important to be considered while studying social marketing.

Another very relevant theory, with its psychological foundations, is the Exchange Theory. The main idea is that humans are need-directed and their key to success is through cooperation and mutually beneficial exchange (Houston \& Gassenheimer, 1987; Layard, 2005 as cited in Hastings, 2007). Relevancy of this theory in marketing was highlighted by Kotler et al., (2001) when he suggests the prerequisites required before an actual exchange can take place, i.e. having at least two parties, each party having something which may be of value to the other party, each party having the capability of communicating and delivering, each party being free to accept or reject the offer (voluntary exchange) and each party believing that it is appropriate or desirable to deal with the other party. Hastings (2007) considersthis theory's role and applicability to both 
commercial and social marketing, saying that the idea of exchanging something intangible also applies to commercial marketing. This theory applies to the concept of exchange as it is embedded within the proposed conceptual framework of our study.

In addition, Social Learning Theory emphasizes on the concept of self-efficacy or in other words, building up the target audience's belief that they can make the behavior happen (Bandura, 1997 as cited in Hastings, 2007). Applying concepts of social marketing to bring about a change in personal development is the very purpose of the current study.A comprehensive social marketing intervention program is the tool that promotes the belief, building upon an individual's self-efficacy, that a behavioral change for personal development is possible. Through the overarching participatory paradigm and community-based approach of the study, participation in the entire process provides motivation, empowerment and ownership to youth further paving the ground for a sustainable attitudinal/behavioral change to occur.

Moreover, Change Theory, also known as the Transtheoretical Model of Behavior Change, evolved from Prochaska and DiClemente's (1983) basic idea that individuals make complex behavioral decisions based on five stages from ignorance of or indifference towards the idea of changing through trial to becoming committed to the new behavior (Hastings, 2007). These stages of change are called pre-contemplation, contemplation, preparation, action and confirmation and have been used in numerous studies to understand at which stage the target audience falls and to design an intervention strategy according to the specific stage (Proschaska \& Velicer, 1997; Andreasen, 1995). In this way, a social marketer may propel the consumer to move through a series of stages which will lead to sustained behavior change, rather than reach the confirmation stage in one step which is usually not the case in very complex behavioral changes, i.e. smoking cessation or weight control (Andreasen, 1995). This theory has not been without its criticism as human behavior is not only complex but challenging and if anything it provides insight into realizing that behavior change is a process rather than an on/off switch (Hastings, 2007). As pre-contemplation and contemplation relates to giving thought to something before doing it, the same is the case when one intends to do something first before actually doing it; the thought of course precedes the action.

Consequently, this study proposes the hypotheses that perhaps even if an actual behavioral change does not occur in some individuals, still some may have given thought or intended to bring about a change in personal development by taking the initiative for personal growth (Robitschek, 1998). Therefore participatory action research methods and a social marketing approach are combined to create and apply a narrative-based curriculum for youth which addressed pressing problems of youth (Hamby, Pierce, Daniloski, \& Brinberg, 2011). Hamby et al. (2011) utilized the posttest control group experiment to evaluate the impact of classroom intervention and concluded that the narrative-based curriculum is more effective, in terms of increasing knowledge and changing attitudes towards sexual behavior and conflict resolution, rather than the regular government based curriculum.

On the basis of initial qualitative research along with the above mentioned concepts within the Social Cognitive Theory and Social Learning Theory, the following hypothesis is proposed. 
$\mathbf{H}_{1}$ :Exposure of social marketing intervention program has significant impact on intention of attaining personal development.

Study by Mohammadi, Schwitzer and Nunnery (2010) examine the effects of residence and gender on college student adjustment in Iran and find that self-efficacy and personal development has no significant influence on gender but that both may be higher among on-campus residential students compared to similarly aged commuter students. A study by Pahl (2011) measures the relationship of two theories of personal development (Chickering's Third Vector, 1993 and Covey's 7 Habits of Highly Effective People, 1989) focusing on gender, freshmen and senior college students and students living on or off campus. However, Pahl (2011) finds females to be more personally developed as compared to males for both scales and there is also evidence to suggest that females developmentally mature earlier than males (Pascarella \& Terenzini, 1991). The inherent differences in the gender and age groups may bring the actual differences in personal development of youth when exposed to social marketing intervention programs. Therefore it is proposed that:

$\mathbf{H}_{2}$ : Exposure of social marketing intervention program has significant impact on intention of attaining personal development among males as compare to females.

Flowers (2002) in his study finds that freshmen and seniors are at two different levels of personal development and suggests based on evidence that there is a difference in the levels of personal autonomy between the two age groups. On the other hand, Pahl (2011) finds that seniors measure significantly higher in developing autonomy, but finds no significant differences between college freshmen and seniors on Covey's self-scoring profile of personal development. Considering this dichotomy in literature the present research proposes that:

$\mathbf{H}_{3}$ : Exposure of social marketing intervention program has significantly different impact on intention of attaining personal development among different age groups, such as, BBA, MBA and working youth.

$\mathbf{H}_{4}$ : There is a statistically significant difference in personal development due to number of workshop sessions attended by the experimental group.

\subsection{Quantitative Research Methodology}

To uncover the internal and external determinants of youth development, initially an exploratory study is undertaken in the form ofqualitative research methods with focus groups and face to face interviews, followed by quantitative inquiry inorder to implement and evaluate social marketing intervention program among youth.

An Experimental Design and Survey

A quasi-experimental design is used to test the impact of social marketing intervention program. Subjects are divided into groups of experimental and control groups. Selected participants for the experimental group were undergone work shop training at Quaid-i-Azam University (QAU), Islamabad, Pakistan.For the experimental group, two classrooms are selected on the basis of purposive sampling. BBA and MBA classes are chosen based on cooperation of the teacher, availability of the students and timings of the courses along with similar demographics as of focus group. QAUis the selected site only for the convenient access but also for the diversity prevailing due to the university's own quota system. Students participated in the two-week workshop consisted of both students from BBA/MBA classes and 20 working youth. Attendance of students 
within the various lectures varied and because the workshop was an entirely voluntary activity, attendance varied from one session to another. Although all youth participants were given the incentives of certificates and tea/snacks, still those who attended, they attended on will and this was also dependent on uncontrollable factors which were more individually based rather than anything else.

Table 3: Details about subjects in experimental \& control groups $(\mathrm{N}=174)$

\begin{tabular}{clc}
\hline Population & N & Frequencie s(\%) \\
\hline Control Group & 89 & \\
Gender & & \\
Male & 59 & 66.3 \\
Female & 30 & 33.7 \\
Age Groups & & \\
BS/(18-20) & 45 & 50.6 \\
MS(21-23) & 30 & 33.7 \\
WrkgYth(24-29) & 14 & 15.7 \\
Experimental Group & 85 & \\
Gender & & \\
Male & 72 & 84.7 \\
Female & 13 & 15.3 \\
Age Groups & & \\
BBA(18-20) & 34 & 40.0 \\
MBA(21-23) & 31 & 36.5 \\
WrkgYth(24-29) 20 & & 23.5
\end{tabular}

Control groups were also chosen through non-random selection; however, groups selected were based on matching characteristics and/or demographics of the experimental groups. A control group of the same department, representative of the BBA class (experimental group), was chosen with a similar mix of gender and age group, but different section (BBA, section B). Because their interaction with the experimental group was possible, another control group from economics department (physically distant from the administrative sciences department) was also chosen to counter the effects of having the experimental group in the same department. Similar demographics in terms of gender and age groups (BS, BBA- section B and MS) were chosen for this control group including a mix of working youth between the ages of 24-29 as shown in Table 3 .

The instrument used in this experiment is a survey adopted from the Seven Habits Profile (AppendixA). This scale is used worldwide, specifically for the seminars/trainings conducted by members of the Franklin Covey Co. and their resources are available for individuals, families, businesses, educational institutions, governments and businesses (profit and non-profit) alike. The Seven Habits Signature Program also begins their program by having all participants take the Seven Habits Benchmark (the same scale as mentioned above) to measure the improvement of an individual's overall effectiveness (Covey, 2005). 
The scale is divided into nine subcategories, that is, the personal bank account, life balance, be proactive, begin with the end in mind, put first things first, think win-win, seek first to understand, synergize and sharpen the saw. The first two categories are related to the foundational principles of the seven habits. All items are measured on a 6point Likert-type scale ranging from (1) "very poor" to (6) "outstanding". Each of the habits, once adopted, results in such outcomes as becoming more self-aware, pro-active, in control of his/her own life, independent and interdependent, self-confident, happier, positive and achieve an overall self-improvement or personal development of the self (Covey, 1998; Pahl, 2011).

Another scale used in this experiment was the Personal Growth Initiative Scale PGIS (Appendix B) by Robitschek (1998) which measures the "intentional thought and behavior directed at change and developing as a person". This scale is used as an additional measurement of personal development whereby intentions are measured which in turn may lead to the behavioral change. This can be considered as the first step towards actually making a particular behavior change, in other words, one first needs to intend on doing something before actually doing it. This directly relates to the Stages of Change Theory (Prochaska \& DiClemente, 1983 as cited in Hastings, 2007). This instrument is used as a further verification of the attitudes of youth and their consequent intentions of bringing about a change in their own personal development.

Materials used in this study include a workbook of approximately fifty pages which assisted the researcher in delivery of the workshop objectives. These workbooks provided participants with examples, relevant quotes, individual and group activities as well as cartoons/illustrations and blank pages for further engagement. The material was adopted from Covey's book of seven habits, his signature program, and online activities relevant to the topics/themes discussed in the workshop. Other visual materials include posters and banners or the print ads used to promote the workshop. All visual materials were displayed from the very first day. The organizers of the workshop received additional instructions and details of the agenda required to conduct the workshop along with the researcher.

Both groups were administered the 7 Habits Survey along with the PGIS Survey by the researcher as a pretest and posttest. The survey was administered through proper protocol, verbally providing instructions and ensuring confidentiality. An informed consent form was not needed in this instance because completion of the survey only took 5-10 minutes. Special care was undertaken to make sure the posttests were administered to the same group of participants (from both department of administrative sciences and economics) and that participants were unaware of the objectives of the study (further improving internal validity of testing effects).

Since the time span for this field experiment was between two-three months, the threats to internal validity, namely history and maturation effects, is negligible due to the control group design. As main testing effect may have occurred during the experiment, as this is an inherent limitation of this type of design, however, the interactive testing effects, is controlled for due to this particular control group design. To counter these possible threats to validity, two control groups were kept so as to nullify the effects of interaction between students in classes of different sections (same departments) causing some attitudinal/behavioral change to occur due to this interaction, rather than the 
intervention program itself. Secondly, the other control group served to nullify this effect in its entirety due to the physical distance between the different departments chosen (economics department). This served to account for validity threats where members "diffuse" and both experimental and control groups talk to each other (Creswell, 2003).

Another threat to validity is the external validity which arises due to generalizations being made beyond the groups in the experiment. This is also taken under consideration and although members assigned to the experimental and control groups were not randomly selected (as in more sophisticated experimental designs), great care was taken to ensure that the groups were as diverse as possible in terms of demographical characteristics, i.e. age, gender, social status. Due to the diversity inherently present within the university's own quota system, there was no reason to believe that the youth groups chosen for the experiment would be any different from any other youth outside of the specific university site chosen for the experiment. The working youth groups for both experimental and control groups were also fresh graduates from private/public universities who had been working in the corporate sector for the past 1-3 years.

Wherever it was possible, the researcher tried to anticipate any confounding or contaminating factors and control for them using this particular experimental design whilst taking into consideration time and costs. The use of the control group not exposed to the intervention but similar to the participants in every possible way, improved this study by helping to rule out any effects of time or other events which may have affected the results. Due to the nature of the study, limitations of this type of design as well as exogenous or "nuisance" variables are further discussed in the limitations section of this study.

\section{Analysis and Results}

sDescriptive statistics, frequencies, paired t-tests and ANOVA, are applied by using the Statistical Package for Social Sciences software (SPSS, version 17.0) for testing the proposed hypotheses. All results are tested at a $1 \%$ level of significance.The 7 Habits and PGI Scales show consistent internal reliability of above 0.7 in all variables of the scale applied to control and experimental groups as highlighted Table 4.

Table 4: Descriptive for Personal Development Scales for Control \& Experimental Groups

\begin{tabular}{|c|c|c|c|c|c|c|c|c|c|}
\hline & \multicolumn{5}{|c|}{ For Control Group N=89 } & \multicolumn{4}{|c|}{ For Experimental Group N=85 } \\
\hline & Scales & $\begin{array}{l}\text { Score } \\
\text { Range }\end{array}$ & Mean & SD & $\alpha$ & $\begin{array}{l}\text { Score } \\
\text { Range }\end{array}$ & Mean & SD & $\alpha$ \\
\hline & 7 Habits & $1.74-5.44$ & 4.18 & 0.75 & 0.90 & $1.81-5.44$ & 4.35 & 0.55 & 0.88 \\
\hline Фّ & $\begin{array}{l}\text { PGIS } \\
7 \text { Habits }\end{array}$ & $\begin{array}{l}1.33-6.00 \\
2.67-5.74\end{array}$ & $\begin{array}{l}4.15 \\
4.08\end{array}$ & $\begin{array}{l}1.00 \\
0.62\end{array}$ & $\begin{array}{l}0.85 \\
0.87\end{array}$ & $\begin{array}{l}2.78-5.89 \\
3.22-5.48\end{array}$ & $\begin{array}{l}4.28 \\
4.66\end{array}$ & $\begin{array}{l}0.62 \\
0.48\end{array}$ & $\begin{array}{l}0.76 \\
0.91\end{array}$ \\
\hline 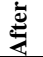 & PGIS & $2.22-5.89$ & 4.13 & 0.78 & 0.79 & $3.33-6.00$ & 4.64 & 0.62 & 0.83 \\
\hline
\end{tabular}

Cronbach Alpha is represented by $\alpha$

Standard deviations (SD) of below one verify that all scales have relatively less dispersion of responses from the mean. In addition, the means for before/after control groups have changed minutely, whereas for before/after experimental groups has obvious difference.As the purpose of this analysis is to compare one group at different points in 
time while applying the social marketing intervention program,paired sample t-test technique is appropriate for pretest/posttest experimental designs (Pallant, 2005). Paired sample t-tests used to evaluate the effect of the social marketing intervention program on personal development using the 7 Habits Scale and the PGI Scale for both control and experimental groups is shown in Table 5.

Table 5: Paired t-Test: Effect of Personal Development in Before and After Control \& Experimental Groups

\begin{tabular}{|c|c|c|c|c|c|c|c|c|c|c|}
\hline \multirow{4}{*}{$\begin{array}{l}7 \quad \text { Habits } \\
\text { Scale } \\
\text { PGI Scale }\end{array}$} & \multicolumn{5}{|c|}{ For Control Group N=89 } & \multicolumn{5}{|c|}{ For Experimental Group N=85 } \\
\hline & $\begin{array}{l}\text { Mean } \\
\text { Before }\end{array}$ & After & $d f$ & $\bar{t}$ & Sig. & $\begin{array}{l}\text { Mean } \\
\text { Before }\end{array}$ & After & $d f$ & $\mathbf{t}$ & Sig. \\
\hline & $\begin{array}{l}4.18 \\
(0.75)\end{array}$ & $\begin{array}{l}4.08 \\
(0.62)\end{array}$ & 88 & 1.19 & 0.24 & $\begin{array}{l}4.34 \\
(0.55)\end{array}$ & $\begin{array}{l}4.66 \\
(0.48)\end{array}$ & 84 & -5.56 & $.000 * *$ \\
\hline & $\begin{array}{l}4.15 \\
(1.0)\end{array}$ & $\begin{array}{l}4.13 \\
(0.78)\end{array}$ & 88 & 0.16 & 0.88 & $\begin{array}{l}4.28 \\
(0.62)\end{array}$ & $\begin{array}{l}4.64 \\
(4.64)\end{array}$ & 84 & -4.39 & $.000 * *$ \\
\hline
\end{tabular}

Note: $* * \mathrm{p}<0.01$, PGI means Personal Growth Initiative Scale

Values in parenthesis indicates SD

$\mathrm{H}_{1}$ is accepted as there is a statistically significant difference in personal development (using both scales) for before (7 Habits Scale: $\mathrm{M}=4.34, \mathrm{SD}=0.55, \mathrm{t}_{(84)}=$ 5.56, $\mathrm{p}<.01$; PGI Scale: $\left.\mathrm{M}=4.28, \mathrm{SD}=0.62, \mathrm{t}_{(84)}=-4.39, \mathrm{p}<.01\right)$ and after (7 Habits Scale: $\mathrm{M}=4.66, \mathrm{SD}=0.48, \mathrm{t}_{(84)}=-5.56, \mathrm{p}<.01$; PGI Scale: $\left.\mathrm{M}=4.64, \mathrm{SD}=0.64, \mathrm{t}_{(84)}=-4.39, \mathrm{p}<.01\right)$ experimental groups due to the implementation of the social marketing intervention program. Whereas, $\mathrm{H}_{1}$ is also proved by evaluating control group, as there is no statistical significance between the means of the personal development scales as no social marketing intervention program is implemented to the control group as evident by 7 Habits Scale for before $\left(\mathrm{M}=4.18, \mathrm{SD}=0.75, \mathrm{t}_{(88)}=1.19, \mathrm{p}<.01\right)$ and after groups $(\mathrm{M}=4.08$, $\left.\mathrm{SD}=0.62, \mathrm{t}_{(88)}=1.19, \mathrm{p}<.01\right)$.Similarly, PGI Scale for personal development for before control group $\left(\mathrm{M}=4.15, \mathrm{SD}=1.01, \mathrm{t}_{(88)}=0.16, \mathrm{p}<.01\right)$ and for after control group $(\mathrm{M}=4.13$, $\left.\mathrm{SD}=0.78, \mathrm{t}_{(88)}=0.16, \mathrm{p}<.01\right)$.

Another way to validate the above findings is through the effect size or the eta squared statistic often used where sample sizes are small (as in experimental designs). This indicates the relative magnitude of the differences between means or the "strength of the association" (Pallant, 2005) and ranges anywhere from zero to one. The eta squared statistic (0.27) for the experimental group for this study indicates a large effect size, in other words, the strength of the difference between the two groups (before and after) is large enough to be significant. This measures the magnitude of the intervention's effect or the proportion of variance between the before and after experimental groups. As per Cohen's (1988) guideline (.01=small effect, .06=moderate, .14=large effect), an eta squared statistic of over 0.14 is considered to have a large effect (Pallant, 2005).

As the objective is to determine whether there are any differences in variance between the groups, therefore there is no need to conduct a post-hoc comparison to determine which group actually is most different. As sample size is above 30, still a more stringent, $1 \%$ level of significance is used for all tests due to the nature of the study which 
involves the interaction between subjects, hence, violating the assumption that all observations are independent (Stevens, 1996 as cited in Pallant, 2005).

ANOVA tests are applied to determine whether there is significant difference between the mean scores of more than two groups, such as, gender, age and number of sessions.Table 5 depicts the descriptive statistic and one-way ANOVA for gender using both scales of personal development and Tables 6 depict the descriptive statistics and one-way ANOVA for age groups using both scales of personal development.

Table 5: Effect of social marketing exposure to gendersfor Personal Development to Experimental Group After by using One-Way ANOVA(N=85)

\begin{tabular}{lllllll}
\hline \hline & \multicolumn{2}{l}{ Mean Scores } & $\boldsymbol{d} \boldsymbol{f}$ & Mean & $\mathbf{F}$ & Sig. \\
\cline { 2 - 7 } & Male & Female & & Sq. & & \\
7 Habits Scale & $\mathrm{n}=72$ & $\mathrm{n}=13$ & & & & \\
& $\mathbf{4 . 4 1}$ & $\mathbf{4 . 3 4}$ & Between Groups $=1$ & 0.05 & 0.13 & 0.72 \\
& $(0.64)$ & $(0.62)$ & Within Groups $=83$ & 0.41 & & \\
PGI Scale & $0.08 \dagger$ & $0.17 \dagger$ & & & & \\
& $\mathbf{4 . 4 6}$ & $\mathbf{4 . 5 0}$ & Between Groups $=1$ & 0.02 & 0.04 & 0.85 \\
& $(0.71)$ & $(0.75)$ & Within Groups $=83$ & 0.51 & & \\
\hline \hline
\end{tabular}

Values in parenthesis indicates SD

Values marked with $\uparrow$ represents standard errors

There is no statistically significant difference in the variability in means of both personal development scales based on gender measured by 7 Habit Scales ( $M=4.41$ vs. 4.34, $\mathrm{SD}=0.64$ vs. 0.62$)$ and PGI Scale $(\mathrm{M}=4.46$ vs.4.50, $\mathrm{SD}=0.71$ vs.0.75) as shown in Table 5. Hence, $\mathbf{H}_{2}$ is not accepted, i.e. there is no statistically significant difference in personal development on the basis of gender.

Table 6: Effect of social marketing exposure to different Age groups on Personal Development for Experimental Group After by using One-Way ANOVA (N=85)

\begin{tabular}{llllllll}
\hline \hline & \multicolumn{2}{l}{ Mean scores } & \multicolumn{1}{c}{$\boldsymbol{d f}$} & Mean & F & Sig. \\
\cline { 2 - 8 } & BBA & MBA & WrkgYth & & Sq. & & \\
& $(18-20)$ & $(21-23)$ & $(24-29)$ & & & & \\
7 Habits Scale & $\mathrm{n}=34$ & $\mathrm{n}=31$ & $\mathrm{n}=20$ & & & & \\
& $\mathbf{4 . 2 6}$ & $\mathbf{4 . 3 1}$ & $\mathbf{4 . 8 0}$ & Between Groups =2 & 1.96 & 5.33 & $.000^{* *}$ \\
& $(0.63)$ & $(0.64)$ & $(0.48)$ & Within Groups = 82 & 0.37 & & \\
PGI Scale & $0.11 \dagger$ & $0.12 \dagger$ & $0.11 \dagger$ & & & & \\
& $\mathbf{4 . 4 3}$ & $\mathbf{4 . 3 2}$ & $\mathbf{4 . 7 4}$ & Between Groups =2 & 1.09 & 2.22 & 0.12 \\
& $(0.70)$ & $(0.70)$ & $(0.70)$ & Within Groups = 82 & 0.49 & & \\
& $0.12 \dagger$ & $0.13 \dagger$ & $0.16 \dagger$ & & & & \\
\hline
\end{tabular}

Values in parenthesis indicates SD, WrkgYth stands for Working Youth

Values marked with $\uparrow$ represents standard errors

$* * \mathrm{p}<0.01$

However, there is a statistically significant difference in the mean scores of personal development between different three age groups when measured by 7 Habits Scale: BBA $(\mathrm{M}=4.26, \mathrm{SD}=0.63), \mathrm{MBA}(\mathrm{M}=4.31, \mathrm{SD}=0.64)$ and Working Youth $(\mathrm{M}=4.80, \mathrm{SD}=0.48)$ as shown in Table 6 . Differences in means are apparent between the 
three age groups for both scales; however, there is only evidence of statistically significant difference or variance between the means of the 7 Habits Scale and not for the PGI Scale. Hence, the $\mathbf{H}_{\mathbf{3}}$ is accepted as there is statistical significance between age groups in their attitudinal/behavioral change towards personal development. Perhaps age is a factor in the intention for personal growth as all age groups do give thought to their own personal development.

Table 7: Assessing the effect of social marketing exposure to personal development between no. of sessions attended by using One-Way ANOVA $(\mathrm{N}=85)$ for after experiment group

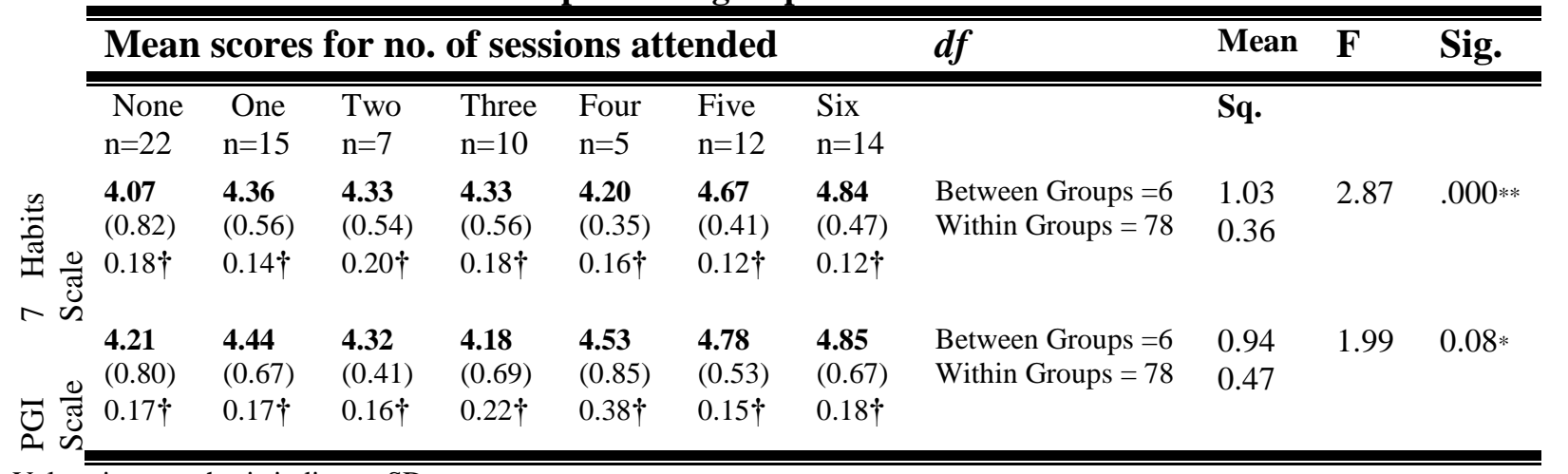

Values in parenthesis indicates SD

Values marked with $\uparrow$ represents standard errors

$* * \mathrm{p}<0.01, * \mathrm{p}<0.10$

Table 7 shows significant difference between the number of workshop sessions attended by the subjects.Subjects who attended all six sessionsare showing greater mean value for personal development as compare to the rest of groups for ( $\mathrm{M}=4.84$ vs.4.07, $\mathrm{SD}=0.47$ vs.0.82) 7 Habit Scale and $(\mathrm{M}=4.85$ vs.4.21, $\mathrm{SD}=0.67$ vs.0.80) PGI Scale. Hence $\mathbf{H}_{4}$ is accepted as there is a statistically significant difference in personal development (7 Habits Scale) due to number of workshop sessions attended by the experimental group.

One-way analysis of variance is accepted at $1 \%$ level of significance for the 7 Habits Scale and accepted at 10\% level of significance for the PGI Scale. Perhaps attendance of the workshop sessions depicts greater commitment to personal development in terms of attitudinal/behavioral change than the intention of attaining personal growth.

\section{Discussion and Conclusion}

Due to the exploratory nature of this study, an initial qualitative study identified the factors of youth development which are contextually relevant thereby achieving the first objective of the current study. After the identification of internal/external determinants of youth development, it became clear that internal factors are the factors which need attention, namely personal factors of development. These factors are not only controllable by the individual, but if harnessed appropriately, could lead to many other favorable outcomes, i.e. more self-confidence, better ability to cope with stress, better decision-making, better interaction with others and better relationships, more positive way of dealing with situations, more happiness... more success. 
Although social marketing is at crossroads with the debate of upstream vs. downstream approach, nevertheless, it is really about what works best for the social marketer (Hastings, 2007). Ideally, the two approaches complement one another as individual behavior change demands the support of the policy change and this works just as well in reverse order. This study emphasizes on the downstream approach as participation and empowerment are the keys to providing the impetus needed to bring about a voluntary behavior change.

Results of the current study shows statistical significance for three out of four hypotheses proposed. Although the experimental design is not a true experimental design (no random assignment of participants), due to certain constraints and limitations of the experimental site, still, two different control groups are used to counter the effects of any extraneous variable which may have affected the personal development as dependent variable.

The quantitative analysis concludes that there is no statistically significant difference in personal development for the control group, whereas there is statistically significant difference in personal development for the experimental group hence proving $\mathrm{H}_{1}$. The main factor is the intervention of the social marketing program which bring differences in personal development of various age groups and number of workshop sessions attended.Results and analysis proves acceptance of all proposed alternative hypothesis except $\mathrm{H}_{2}$, which verifies that there is no statistically significant difference in attitudinal/behavioral change towards personal development on the basis of gender. Similar results are found in a study by Mohammadi, Schwitzer and Nunnery (2010) while examining the effects of residence and gender on college student adjustment in Iran and find that self-efficacy and personal development has no significant influence on gender but that both may be higher among on-campus residential students compared to similarly aged commuter students. In the present study, due to uncontrollable factors and the pure voluntary aspect of the workshop, the sample consists of much less females than males (15\% females; $85 \%$ males) due to which sound statistical evidence may not have been possible. However, in terms of the self-reported feedback which females gave as compared to males, the seriousness and level of maturity is quite evident as is the level of participation of the elder female crowd, hence the results are consistent with that of Pascarella \& Terenzini (1991).

As Flowers (2002) finds that freshmen and seniors are at two different levels of personal development and basedon evidence suggests that there is a difference in the levels of personal autonomy between the two age groups as well. Pahl (2011) finds that seniors measure significantly higher in developing autonomy, but finds no significant differences between college freshmen and seniors on Covey's self-scoring profile of personal development. Similarly in the current study, there is no significant difference in the PGI Scale but there is significant difference in the 7 Habits Scale between the three age groups where the working youth age group (24-29) depicts the greatest difference in means from the younger groups. One plausible explanation is that Covey's scale is more focused on long-term development of youth into adulthood and is, therefore, not meant for only short-term student development. In terms of qualitative analysis, a stark difference is observed among the attitudes of the younger age groups (BBA students) as compared to the elder group (working youth). The level of maturity and hence, 
seriousness for bringing about a change in oneself in terms of personal development is evident among most MBA students and working youth. Subsequently, convincing and motivating the younger age groups through social marketing tactics is clearly more challenging.

This study finds a statistically significant difference between before and after experimental groups to which the social marketing intervention program is introduced for the intention of attaining personal development as well as in having an attitudinal/behavioral change in personal development (H1). Similar results are found by Conrad and Hedin (1981) who studied the impact of positive youth development through a variety of experiential education programs using pre and post-program surveys. Conrad and Hedin(1981) find that students in the experimental group demonstrated improvement in personal and social development, self-esteem, moral reasoning and improved attitude toward involvement and participation in community service. Through a meta-analysis of 25 program evaluations using a strong research design of comparison groups, Catalano et al. (1998) also find significant effects of positive behavioral outcomes related to personal and social development, i.e. self-esteem, problem-solving, interpersonal skills, social acceptance and self-efficacy.

\subsection{Recommendations}

The current study has significant and broad-based ramifications for policymakers, government, NGOs, public/private industry sector, educational institutions and/or other stakeholders. Moreover, educational institutions can develop programs and activities to promote and instruct positive behaviors for personal development of youth in order to groom them into the successful leaders and policy-makers of the future. As youth are the future nation-builders, developing a positive and productive youth would not only be a vital human resource but also a social and economically viable asset for all stakeholders in any society.

\section{References}

Andreasen, A.R. (1995).Marketing social change: Changing behavior to promote health, social development and the environment. San Fransisco, CA: Jossey-Bass.

Andreasen, A. R. (2002). Marketing social change in the social change marketplace. Journal of Public Policy \& Marketing, 21(1). 3-13.

Andreasen, A. R. (2006).Social marketing in the $21^{\text {st }}$ century. Thousand Oaks, CA: Sage Publications.

Bandura, A. (1986). Social foundations of thought and action: A social cognitive approach. Englewood Cliffs, NJ: Prentice-Hall.

Bandura, A. (1997).Self-efficacy: The exercise of control. New York, NY: Freeman.

Benson, P. L., \& Saito, R. N. (1998). Youth development: Issues, challenges and directions, chapter on the scientific foundations of youth development. Retrieved from http://www.ppv.org/ppv /publications/assets/74_publication.pdf 
Catalano, R. F., Berglund, M. L., Ryan, J. A. M., Lonczak, H. C., \& Hawkins, J. D. (1998). Positive youth development in the United States: Research findings on evaluations of positive youth development programs. Retrieved from http://www.ppv.org/ppv /publications/assets/74_publication.pdf

Conrad, D., \& Hedin, D. (1981). National assessment of experiential education: A final report. St. Paul, MN: University of Minnesota. Retrieved from http://www.ppv.org/ppv /publications/assets/74_publication.pdf

Covey, S. R. (1989). The 7 habits of highly effective people: Powerful lessons in personal change. Free Press.

Covey, S. R. (1994). Effective leadership begins with seven habits: An interview with Stephen R. Covey. Journal of the American Dietetic Association, 94(4), 382.

Covey, F. (1998). Frankly Covey: Seven Habits Profile [Self Scoring Seven Habits Profile]. Unpublished instrument. Retrieved from http://www.franklincovey.com ltc/resources

Covey, S.C. (2005). The 7 habits of highly effective people: Signature program. Franklin Covey.

Creswell, J.W. (2003). Research design: Second edition. Thousand Oaks, CA: Sage Publications. Inc.

Domegan, C. T. (2008). Social marketing: Implications for contemporary marketing practices classification scheme. Journal of Business and Industrial Marketing, 23(2). 135-141.

Flowers, L. A. (2002). Developing purpose in college: Differences between freshmen and seniors. College Student Journal, 36(3), 478. Greenwald, H.P., Pearson, D., Beery, W.L., \& Cheadle, A. (2006). Youth development,community engagement, and reducing risk behavior, The Journal of Primary Prevention, 27(1).

Hamby, A., Pierce, M., Daniloski, K., \& Brinberg, D. (2011). The use of participatory action research to create a positive youth development program. Social Marketing Quarterly, 17(3), 2-17.

Hastings, G. (2007). Social marketing: Why should the devil have all the best tunes? Burlington, MA: Elsevier Ltd.

Houston, F.S., \& Gassenheimer, J.B. (1987). Marketing and exchange. Journal of Marketing, 51(10), 3-18.

Janjua, Y., Ahmed, F., \& Mahmood, A. (2011). Roundtable Report on Youth Development and Economic Growth, Centre for Poverty Reduction and Social Policy Development Planning Commission, Government of Pakistan: A project of UNDP and the Government of Pakistan. Retrieved from http://www.cprspd.org /Report\%20-\%20Youth\% 20Roundtable.pdf 
Khalid, M. (2003). Social Problems of Pakistan. Karachi, Pakistan: Kifayat Academy. Educational Publishers.

Kotler, P., Brown, L., Stewart, A., \& Armstrong, G. (2001). Marketing (5 ${ }^{\text {th }}$ ed.). Upper Saddle River, NJ: Prentice Hall.

Layard, P.R.G. (2005). Happiness: Lessons from a new science. London, UK: Allen Lane.

Lefebvre, C. R. (2011). An integrative model for social marketing. Journal of Social Marketing, 1(1), 54-72.

McKenzie-Mohr, D. (2000). Promoting sustainable behavior: An introduction to community-based social marketing. Journal of Social Issues, 56(3), 543554.

Mohammadi, M., Schwitzer, A. M., \& Nunnery, J. (2010). Examining the effects of residence and gender on college student adjustment in Iran: Implications for psychotherapists. Journal of College Student Psychotherapy, 24(1), 59-72.

Pahl, C.M. (2011). Moving through autonomy toward interdependence: the relationship between Chickering and Reisser's third vector and Stephen Covey's Seven habits of highly effective people (Master's theses, Eastern Illinois Univerisity, Illinois). Retrieved from http://thekeep.eiu.edu/theses/170

Pallant, J.F. (2005). SPSS survival manual: A step by step guide to data analysis using SPSS for Windows (version 12). Ligare, Sidney: Allen \& Unwin.

Pascarella, E.T., \& Terenzini, P.T. (1991). How college affects students. San Francisco, CA: Jossey-Bass.

Pittman, K. J., O'Brien, R., \& Kimball, M. (1993). Youth development and resiliency research: Making connections to substance abuse prevention. New York, NY: Center for Youth Development and Policy Research/Academy for Educational Development.

Prochaska, J.O. \& DiClemente, C.C. (1983). Stages and processes of self-change ofsmoking: toward an integrative model of change. Journal of Consulting and Clinical Psychology, 51(3), 390-395.

Robitschek, C. (1998). Personal growth initiative: The construct and its measure. Measurement and Evaluation in Counseling and Development, 30,183198.

Sekaran, U., \& Bougie, R. (2010). Research methods for business: A skillbuilding approach ( $5^{\text {th }}$ ed.). New Delhi, India: Student Book Company.

Stead, M., Gordon, R., Angus, K., \& McDermott, L. (2007). A systematic review of social marketing effectiveness. Health Education, 107(2), 126-191.

Stevens, J. (1996). Applied multivariate statistics for the social sciences (3rd edition).Mahway, NJ: Lawrence Erlbaum. 


\section{Appendix A}

Seven Habits Scale (Covey, 1998)

1. I show kindness and consideration towards others.

2. I keep promises and honor commitments.

3. I do not speak negatively of others when they are not present.

4. I am able to maintain an appropriate balance among the various aspects of my life,work, friends, and so forth.

5. When working on task, I also keep in mind the concerns and needs of those I am working for.

6. I work hard at things I do, but no in a manner that causes burnout.

7. I am in control of my life.

8. I focus my efforts on things I can do something about rather than on this beyond my control.

9. I take responsibility for my moods and actions rather blame othersand circumstances.

10. I know what I want to accomplish in life.

11. I organize and prepare in a way that reduces having to work in crisis mode.

12. I begin each week with a plan of what I desire to accomplish.

13. I am disciplined in carrying out plans (avoiding procrastination,time wasters, and so forth).

14. I do not allow the truly important activities of my life to get lostin the busy activities of my day.

15. The things I do everyday are meaningful and contribute to my overall goals in life.

16. I care about the success of others as well as my own.

7. I cooperate with others.

18. When solving conflicts, I strive to fine solutions that benefit all.

19. I am sensitive to the feelings of others.

20. I seek to understand the viewpoints of others.

21. When listening, I try to see things from the other persons point of view, not just my own.

22. I value, and seek out, the insights of others.

23. I am creative in searching for new and better ideas and solutions.

24. I encourage others to express their opinions.

25 . I care for my physical health and well being.

26. I strive to build and improve relationships with others.

27. I take time to find meaning and enjoyment in life.

Appendix B

Personal Growth Initiative Scale (Robitschek, 1998) 
1. I know how to change specific things that I want to change in my life.

2. I have a good sense of where I am headed in my life.

3. If I want to change something in my life, I initiate the transition process.

4. I can choose the role that I want to have in a group.

5. I know what I need to do to get started toward reaching my goals.

6. I have a specific action plan to help me reach my goals.

7. I take charge of my life.

8. I know what my unique contribution to the world might be.

9. I have a plan for making my life more balanced.

Bothe scales are asked on a scales as $1=$ Very Poor to $6=$ Outstanding 